\title{
ISMAEL SÁNCHEZ BELLA Y SU CONTRIBUCIÓN AL CONOCIMIENTO Y ESTUDIO DEL DERECHO INDIANO
}

\author{
José Antonio González Pizarro \\ Universidad Católica del Norte (Sede Antofagasta) \\ "Indudablemente, Sánchez Bella, junto con Rafael Altamira, \\ Antonio Muro Orejón, Alfonso García Gallo y Juan \\ Manzano, constituyen los máximos exponentes de la historia \\ del derecho indiano del siglo XX" \\ Dr.José Luis Soberanes Fernández, Director del Instituto de \\ Investigaciones Jurídicas de la UNAM. ${ }^{1}$
}

La personalidad de Ismael Sánchez Bella en el mundo de la historia del derecho español y, fundamentalmente, el indiano, es vastamente conocida. Sus penetrantes investigaciones han sido registradas por los principales historiadores americanistas, cuando se ha tratado de precisar la organización financiera temprana del Nuevo Mundo - la implantación del sistema de fiscalización de las autoridades indianas, o bien seguir las conclusiones a que llegan sus investigaciones en el ámbito de las fuentes jurídicas castellano - indianas, para modelar la estructura político - administrativa, o visualizar de qué forma fueron cautelados por la monarquía los derechos de los nuevos súbditos del Nuevo Mundo.

Si esto sucede en el campo intelectual, Sánchez Bella descuella en otros órdenes de cosas, como su bonhomía y calidad humanas y su propia formación universitaria. Esta última le unió al macizo magisterio de Alfonso García Gallo, entre los años 1940 a 1943 en Valencia y más tarde, entre 1946 a 1949,como Profesor Adjunto de su maestro en la Cátedra "Historia de las Instituciones Políticas y Civiles de América" del Doctorado de Derecho de la Universidad Complutense de Madrid y en la de "Derecho Indiano" de la Facultad de Filosofía y Letras. Pero, también, pudo disfrutar de las orientaciones de los profesores Vicente Rodríguez Casado, Juan Manzano y Antonio Muro Orejón, durante su estada, como becario del Consejo Superior de Investigaciones Científicas, en la Escuela de Estudios Hispanoamericanos y en el Archivo de Indias, entre 1943-1946, en Sevilla.

\footnotetext{
${ }^{1}$ Comentario a la obra de SÁNCHEZ BELLA, Ismael, La organización financiera de las Indias (Siglo XVI). Escuela Libre de Derecho-Miguel Angel Porrúa, México, 1990, en Boletín Mexicano de Derecho Comparado, México, 1992, vol.73.
} 
Entre 1946-1947 obtiene su Diplomado en Estudios Hispanoamericanos por la Facultad de Filosofía y Letras de la Universidad de Sevilla y el Doctorado en Derecho por la Universidad Complutense de Madrid.

Tempranamente, se aprecia en su vida las dos vertientes que van a caracterizar tanto su producción académica como el despliegue de su docencia: la obtención, por oposición de la Cátedra de Historia del Derecho Español de la Universidad de La Laguna, en 1949, y su nombramiento como el primer titular de la Cátedra de "Historia de España" de la Facultad de Filosofía y Letras de la Universidad Nacional del Litoral (Rosario de Santa Fe, Argentina). Los dos mundos, el ibérico y el americano, constituirán, desde entonces, el gran espacio de sus inquietudes intelectuales.

A esta faceta académica habrá que incorporar otra, quizás, la más importante, pues encierra la clave de su estatura humana, generosidad para con todos sus discípulos pero, también, no en menor medida, la aproximación a la comprensión históricocultural de las realizaciones hispanas durante tres siglos en América: nos referimos a la profunda convicción de su fe católica y el claro testimonio de esta en su vida personal y universitaria.

Este año 2.002 guarda especial importancia en la vida de D. Ismael: un 2 de abril de 1922 su nacimiento, por lo que cumple ochenta años; en 1952 es nombrado Profesor Ordinario de la Cátedra de Historia del Derecho en la Universidad de Navarra. Centro de Estudios Superiores, fundado, ese año, por José María Escrivá de Balaguer, quien fue su primer Gran Canciller, del cual D, Ismael contribuiría a cimentar su consolidación y prestigio internacional, como su primer Rector (1954-1959) y como Vicerrector (1959-1986), manteniendo su cátedra de Historia del Derecho.Para el que esto escribe, desde hace veinte años me une no sólo el afecto del discípulo sino la admiración por su obra histórico- jurídica y la distinción de su amistad invariable, nacida en los días otoñales de 1982 cuando comencé mis estudios de Doctorado bajo su guía. Sean, pues, estas modestas páginas, el tributo a su octogésimo aniversario, dedicadas a espigar en sus distintas investigaciones sobre el Derecho Indiano, su concepción histórico - jurídica y destacar en este inmenso campo sus contribuciones más sobresalientes para la comprensión de sus instituciones.

Hemos indicado que su formación universitaria, en Valencia, Sevilla y Madrid. estuvo unida al magisterio del que ha sido considerado el renovador de los estudios históricos jurídicos españoles, D. Alfonso García Gallo, cuya copiosa obra, en lo que importa al conocimiento del Derecho Indiano, se encuentra recogida en sus Estudios de Historia del Derecho Indiano (Madrid, 1972), Lọs orígenes españoles de las instituciones indianas (Madrid, 1987) y su insoslayable Metodología de la Historia del Derecho Indiano (Santiago de Chile, 1974). La postura metodológica de García Gallo fue defender la construcción dogmática, la naturaleza jurídica de las instituciones 
(ante las consideraciones político, cultural, social, económico; o sea centrarse exclusivamente desde la historia) conjuntamente con el estudio de las fuentes, éditas o inéditas; en este último caso, la preocupación por examinarlas prolijamente y publicarlas, fueron los principios rectores del influjo de García Gallo, que el discípulo evocaría constantemente ${ }^{2}$. Después de García Gallo, los profesores que influyeron en sus "estudios americanistas", Antonio Muro Orejón y Juan Manzano Manzano, que reforzaron su dilección por las fuentes legislativas y la comprensión por el ambiente en que se gestó y desplegó el Derecho Indiano ${ }^{3}$. Si se examinan los estudios de Sánchez Bella es posible advertir de qué forma guarda fidelidad a los preceptos de García Gallo; y también, de qué manera acoge una apertura hacia los materiales no legales, para la comprensión histórico - jurídica sea de una etapa de la monarquía española en América, la presencia de alguna institución transterrada desde la península o la obra de alguna autoridad relevante o un jurista de nota en las tierras americanas.

En su tesis doctoral expone con claridad la complejidad que exige entender América en los siglos de la monarquía española. Escribe:

"No cabe duda que, por la extensión del tema, sólo podrá tenerse una visión completa del mismo (el tema de la Hacienda) con el fraccionamiento del campo a investigar en una serie de trabajos monográficos, entre los que destacarían, por la importancia del objeto, los referentes al tributo, "quinto" de los metales, ingresos eclesiásticos, y gastos de la Hacienda, que aclararían numerosos aspectos de la vida económico - social de las indias... El estudio de la organización administrativa de la Hacienda indiana permite adentrarse en el conocimiento de un campo más vasto: el del gobierno español en las Indias. Es conocida la política de contrapesos ejercida por la Corona para el gobierno de aquellos lejanos territorios. Los funcionarios del Fisco tienen esa política, por la gran confianza de que gozan en los organismos metropolitanos, un papel importante, en algún momento decisivo, de fiscalización e incluso de freno a una posible extralimitación de los gobernantes indianos. Conocer su actuación es, muchas veces, la clave de sucesos políticos mal comprendidos. Aparte de ese papel político, muchas veces poco visible, de los Oficiales Reales de la Hacienda, observarlos en el ejercicio de sus ocupaciones habituales nos permite comprender la importante función social que desempeñan en las nacientes comunidades" ${ }^{4}$.

\footnotetext{
"SÁNCHEZ BELLA, Ismael, "García Gallo y el Derecho Indiano", Homenaje a la Memoria de Don Alfonso García Gallo, Editorial Complutense, Madrid, 1995, recogido en SÁNCHEZ BELLA, Ismael, Nuevos estudios de Derecho Indiano, Ediciones Universidad de Navarra, S.A., Pamplona, 1995, 391-404: "García Gallo ha sido, para todos, un Maestro ejemplar y su sólida obra científica seguirá manteniendo permanentemente su reconocido valor" p. 404.

${ }^{3}$ SÁNCHEZ BELLA Ismael, "La organización financiera de las Indias (Siglo XVI)", Escuela de Esstudios Hispanoamericanos, Sevilla, 1968, 7.

`SÁNCHEZ BELLA, Ismael, La organización financiera de las Indias, op.cit. 5.
} 
En 1983, con ocasión del Primer Seminario de Historia del Derecho Venezolano, llamaba la atención sobre el uso de otros repertorios documentales para tener un conocimiento cabal de las instituciones de aquella república bajo la monarquía hispánica. En esa oportunidad, les planteó a sus colegas sudamericanos:

"De las fuentes no estrictamente legales que también son de interés para el estudio de las instituciones venezolanas, sólo ha existido en los distintos países una preocupación generalizada por la edición de las actas de los Cabildos... Sin embargo, existen otras tanto o más importantes para el Derecho Indiano. Por ejemplo, para el extenso estudio de la organización de la Real Hacienda Indiana en el siglo XVI que publiqué en 1968, fue fundamental el "Libro de Acuerdos" de los Oficiales Reales de Venezuela publicado en Caracas en 1945 bajo el título de "Orígenes de la Hacienda en Venezuela". Bajo el gobierno de España, hubo en América "libros de Acuerdos" no sólo de la Hacienda, sino de otros organismos como las Audiencias... Convendría también reunir y publicar los Autos de ambas Audiencias referidos a territorios venezolanos... Sería conveniente dar a conocer una cuidada selección de documentos notariales, es decir, documentos de aplicación en Venezuela del derecho privado, tan emparentado con el castellano de las Partidas y el Fuero Real... También habría que abordar la publicación de parte de la correspondencia enviada desde Venezuela por las autoridades civiles y eclesiásticas... No podemos olvidar que el Derecho indiano fue el fruto de un constante y fecundo diálogo entre las autoridades peninsulares y las de Indias y que las Reales Cédulas y capítulos de cartas del Rey y el Consejo de Indias a los gobernantes de Venezuela se complementan con la correspondencia enviada a España desde estos territorios"

Afirmación que vendría a refrendar lo puntualizado en 1972 en atención a que la propia realidad americana no se podía contener en lo recogido por la copiosa legislación del tiempo de la monarquía castellana. En esa ocasión aseveró:

"Somos muchos los que no contentos con el conocimiento de la norma elaborada para las Indias, desearíamos conocer la realidad americana con la mayor exactitud posible. Los textos legales no nos satisfacen plenamente porque aunque en muchos de ellos la exposición de motivos aluda al hecho que da vida a la disposición, la

${ }^{5}$ ISMAEL SÁNCHEZ, Bella, "Edición de fuentes para el estudio de las instituciones de Venezuela", en SÁNCHEZ BELLA, Nuevos estudios de Derecho Indiano, op.cit.125-126. En el "debate" suscitado en las IV Conversaciones Internacionales de Historia, celebradas en marzo de 1988 en la Universidad de Navarra, Pamplona, SÁNCHEZ BELLA afirmaría, ante una pregunta del historiador sueco Magnus Mörner, "Todo lo referente a la vida judicial en el campo... es una cosa que se desconoce, lo mismo que antes decían que el gran problema de la propiedad es conocer la realidad (una cosa son las leyes y otra la realidad). Pienso que todos los temas de la vida rural se nos escapan bastante todavía". Cf. Balance de la historiografía sobre Iberoamérica (1945-1988), Ediciones Universidad de Navarra, S.A., Pamplona, 1989, 444. 
referencia es, casi siempre, excesivamente parca, y hay muchos hechos que no han producido normas.

Las cartas de Indias son, en cambio, una fuente importante para conocer esa realidad indiana, siempre que sean utilizadas con prudencia y en su debida valoración. Como es sabido, la libertad de escribir a la Corte los residentes en las Indias no sólo era tolerada sino estimulada por los reyes... Para conocer la gestión de los virreyes indianos, no nos bastan las relaciones o memorias de gobierno que dejan a sus sucesores, difícilmente objetivas, ni conocer el dictamen del fiscal del Consejo y la sentencia de los juicios de residencia a que son sometidos al terminar su mandato... la lectura de las cartas de Indias pueden dar luz sobre aspectos no conocidos... la de los oficiales reales de la Hacienda de la caja de Lima de mediados del siglo XVI me permitió descubrir la causa principal, no bien comprendida, de la destitución por Felipe II de dos virreyes peruanos: Andrés Hurtado de Mendoza, marqués de Cañete, y el conde Nieva" ${ }^{6}$.

La visión que se forma de los tres siglos de la América hispánica, desde la rigurosidad de la documentación y su cotejo con otras fuentes, impresas o no, es importante tenerla presente. Concepción que realza su competencia en la materia, en cuanto a sus dotes metodológicas y, admirando la obra señera de la monarquía española en estas tierras, con objetividad se acerca a los asuntos abordados, buscando la verdad histórica; no aquella de la leyenda dorada de la legislación real y de las instituciones como tampoco rechazando las advertencias provenientes de los propios funcionarios de la monarquía, sean eclesiásticos o civiles, que han dado pie a la propagación de la denominada leyenda negra. En Sánchez Bella, es posible atisbar el mayúsculo esfuerzo en brindar un panorama lo más próximo a la realidad tanto jurídica como cotidiana de la aplicación del derecho, huyendo de expresiones arraigadas, como aquella de los "contrapesos" entre los poderes de las autoridades e instituciones indianas, para rectificar, innovar o ratificar lo que la propia documentación e investigaciones más serias avalan. En ello, se aprecia su preocupación fundamental de atender el repertorio jurídico, la compulsa de fuentes, la búsqueda en archivos y, a partir del desvelamiento de un hecho político o social, cómo operó la norma. En todo ello, revisa críticamente las numerosas contribuciones de los especialistas de ambos lados del Atlántico, para matizar sus conclusiones.

Sin embargo, en esta visión, podemos reconocer tres ejes pivotales: 1. El esfuerzo de la monarquía de los Hasburgos en la fidelidad a la fe católica. Desconocer el factor religioso, sea de las empresas internacionales o en las políticas llevadas a cabo en

"SÁNCHEZ BELLA, Ismael, "Los Visitadores Generales de Indias y el gobierno de los Virreyes" Anuario de Estudios Americanos, vol.29 (Sevilla, 1972), en SÁNCHEZ BELLA, Derecho Indiano. Estudios I. Ediciones Universidad de Navarra, Pamplona, 1991, 197-199. 
el Nuevo Mundo, es desatender una de las claves genésicas e interpretativas respecto del Derecho Indiano. 2.El valor del rescate y publicación de las fuentes del Derecho Indiano y 3. La necesidad de la interdisciplinariedad, o bien complementación, para entender el fenómeno histórico -jurídico de la América hispánica.

1. En su obra magna que es La organización financiera de las Indias, reconocida por el historiador francés Henry Lapeyre como un "classique de l'histoire hispanoaméricaine" ${ }^{7}$, se pueden leer las aseveraciones siguientes:

"La política internacional de la Monarquía española estuvo orientada fundamentalmente durante todo el siglo XVI hacia un objetivo: la defensa de la $\mathrm{Fe}$ Católica. Esta finalidad lleva a Fernando el Católico y a Carlos $V$ a intentar restablecer la armonía entre los cristianos para juntar los esfuerzos contra el Turco, y a Felipe II a esforzarse por salvar la Fe Católica en el mayor número posible de territorios. El esfuerzo fue gigantesco y agotador, en hombres y dinero, y tras él se produce una larga etapa de postración nacional.

Las lejanas y fabulosas Indias juegan un papel importantísimo en esa política internacional de la Monarquía española. Sus riquezas son el principal soporte financiero de las grandes empresas europeas y africanas de los Reyes... Tenemos aquí nuevos testimonios de esa total identificación de ideales entre los castellanos y sus Monarcas, que producía estupor a algunos de los Embajadores extranjeros y que reconocen historiadores tan poco sospechosos como Ranke y Merriman. De España a Indias todos se sentían unidos en una gran empresa común espiritual. Para llevarla a cabo, hacían falta abundantes medios materiales y así hubo que crear una vasta organización financiera que crecía al compás de la rápida expansión por los territorios indianos. Exponer esa organización es el objeto del presente estudio" ${ }^{\prime 8}$.

No obstante, declarar aquello no significaba desconocer la influencia de otros factores en el transcurso del despliegue de la estructura administrativa y de la legislación en América. Reconociendo que la Corona expresó un "afán ordenancista, presente en todas las manifestaciones de la vida indiana" ", los elementos económicos pueden aportar claves para comprender no sólo el gobierno en Indias sino su Derecho criollo, pues, como sentenciara en 1960 al dar a luz su monografía sobre "El Gobierno del Perú:1556-1564": "A lo largo de este trabajo se habrá podido observar que cuando

\footnotetext{
'Citado por PURROY TURRILLAS, Carmen, "Cinco libros del Dr.SÁNCHEZ BELLA sobre Derecho Indiano", en Homenaje a SÁNCHEZ BELLA, Ismael, Universidad de Navarra, Servicio de Publicaciones de la Universidad de Navarra, Pamplona, 1992,49.

"SÁNCHEZ BELLA, Ismael, La organización financiera de las Indias, op.cit .pp. 1,3 y 4.

"SÁNCHEZ BELLA, Ismael, "El Tribunal de Cuentas de México (Siglo XVII)", en SÁNCHEZ BELLA, Derecho Indiano. Estudios II, Ediciones Universidad de Navarra, S.A., Pamplona, 1991,636.
} 
se estudian los episodios de Indias a la luz de los problemas financieros de la Corona, cobran aquéllos nuevas perspectivas"

2. El tema de las fuentes jurídicas legales ha constituido una constante en sus investigaciones, no sólo en el campo del Derecho Indiano sino también estrictamente peninsular, como ha tenido ocasión de llamar la atención el catedrático español Manuel J. Peláez, al referirse al cultivo por parte de nuestro autor de "otras materias iushistóricas tanto en su investigación como en la docencia" ${ }^{11}$.

Fue precisamente la cuestión de las fuentes legales lo que abrió, en 1947, su largo recorrer en el campo del Derecho Histórico. Ese año vio luz su "Edición y utilización de nuevas fuentes para el estudio de las instituciones indianas" en el volumen 18 del Anuario de Historia del Derecho Español.

En la "Introducción" al trabajo de "Los Comentarios a las Leyes de Indias", de 1954, señalaba que la literatura jurídica española ofrecía un peculiar interés a los interesados por los problemas histórico - jurídicos, no sólo por la riqueza y variedad sino por la exigencia de renovar los métodos ante la "multitud de problemas nuevos que plantea el descubrimiento de América". Y este puñado de obras ya había despertado la atención de los historiadores americanistas que, por ser el Derecho Indiano común a todas las naciones del continente, atraía y tenía una mayor preocupación sobre el derecho peninsular. En esa oportunidad, la contribución de Sánchez Bella discurrió en los sendos estudios a las Notas de Prudencio Antonio Palacios y a las Notas de José Lebrón; Notas, ambas, relativas a la Recopilación de las Leyes de Indias de 1680.

De esta exploración en los documentos inéditos refrendó su impresión, en cuanto "desvalorar todavía más la obra y la figura de (Manuel José de) Ayala" y sentar, con rasgos indelebles, una lección para los futuros historiadores del Derecho Indiano:

${ }^{10}$ SÁNCHEZ BELLA, Ismael, "El Gobierno del Perú: 1556-1564", en SÁNCHEZ BELLA, Derecho Indiano. Estudios II, op.cit.464. En las páginas iniciales a este estudio se hace cargo de la frase "la Historia de la América española está aún por hacer", acotando que, a pesar de estar convirtiéndose en "un tópico injustificable... conserva, desgraciadamente, todo su valor para extensos períodos de aquella Historia. Tal es el caso del Virreinato peruano en el período inicial de su organización, a mediados del siglo XVI. Una revisión, no exhaustiva, de las fuentes, como la que aquí se va a realizar, pondrá de relieve la superficialidad de las construcciones históricas con que contamos para el conocimiento de esta etapa tan interesante de la historia hispanoamericana" (Op.cit.p.349)

${ }^{11}$ PELAEZ Manuel J., "Notas sobre SÁNCHEZ BELLA, Ismael y la enseñanza del Derecho Indiano", en Homenaje a Ismael SÁNCHEZ BELLA, op.cit. 36, nota 14. Alli cita: Génesis del Estado Moderno, Pamplona, 1965; co-autor del libro colectivo de José Luis Comellas et.al., La Revolución Francesa. Ocho estudios para entenderla, Pamplona, 1990; "La reforma de la Administración Central en 1834 ". Actas del III Symposium de Historia de la Administración, Madrid, 1974; y la monumental edición de El Fuero Reducido de Navarra, Pamplona, 1989 
“Conocer el Derecho no es todavía aplicarlo. A ello se oponían en Indias numerosos factores: abuso de poder de las autoridades indianas, respaldadas, en parte, en la facultad legal de detener la aplicación de disposiciones, si se estima que el llevarlo a cabo puede ser perjudicial; negligencias de los funcionarios, facilitadas por las largas distancias, que impiden un control eficaz, y, sobre todo, los fuertes intereses económicos de los colonos, que pugnan contra el idealismo de la legislación. Son necesarias numerosas investigaciones parciales para lograr conocer cuál fue el verdadero grado de aplicación del Derecho indiano. En la literatura jurídica indiana se recogen datos sueltos, casi siempre experiencias personales. También Palacios y Lebrón recogen algunos en sus Notas a la Recopilación, aunque desgraciadamente no sean muy abundantes. Precisamente son estos datos uno de los elementos valiosos que ofrecen estas Notas " ${ }^{12}$.

La predilección por los textos perdidos en archivos y manuscritos notables de copias de obras señeras del Derecho Indiano ha sido, desde entonces, un rasgo de sus comunicaciones presentadas en innumerables congresos y jornadas sobre esta disciplina histórico - jurídica. Así, lo demuestran su atención por Rodrigo de Aguiar y Acuña y los Sumarios de la Recopilación General de las Leyes, Ordenanzas, Provisiones, Cédulas, Instrucciones y Cartas Acordadas que por los Reyes Católicos de Castilla se han promulgado, expedido y despachado para las Indias Occidentales, Islas y Tierra Firme del Mar Océano, desde el año de mil y quatrocientos y noventa y dos, que se descubrieron, hasta el presente de mil seiscientos y veinte y ocho, cuya edición y las copias sucesivas llenaron un vacío de fuentes en México y vincular esta obra de 1628 con la que vaya a publicar Juan Francisco de Montemayor de Córdoba y Cuenca, en 1678, como continuación de la de Aguiar. Para Sánchez Bella, el análisis del Cedulario mexicano de Montemayor lo condujo a abordar dos problemas: si era cierta la sospecha de que a partir de "1635, la Recopilación puede tener lagunas significativas, y también saber qué textos legislativos se conocían realmente por autoridades y jueces de México" $^{13}$.

De igual modo, en el II Congreso del Instituto Internacional de Derecho Indiano, verificado en Santiago de Chile, pudo ampliar las noticias sobre dos juristas del siglo XVII, Gaspar de Escalona y Agüero y Juan Luis López, destacando de este último que bien podría "encabezar la serie de los historiadores del Derecho Español", pues su Historia iuridica de el derecho i Gobierno de los Reinos i Provincias de el Perú, Tierra Firme i Chile, al Rei en su Consejo de Indias que bien pudo ser la "primera historia del

\footnotetext{
${ }^{12}$ SÁNCHEZ BELLA, Ismael, "Los Comentarios a las Leyes de Indias" en Derecho Indiano. Estudios II, op.cit.251. El enjundioso estudio corre entre las páginas $89-275$ y constituye un insuperable panorama que puede complementarse con sus otros "descubrimientos" de manuscritos.

SÁNCHEZ BELLA, Ismael, "Publicación de los "Sumarios" de Aguiar (1628) y su utilización en España e Indias", en SÁNCHEZ BELLA, Derecho Indiano. Estudios II, op.cit.315-316.
} 
Derecho Indiano, quedó reducida, pues, a unos valiosos materiales y a unas brevísimas indicaciones que los acompañaron sobre los gobernantes que tuvo el Perú hasta $1674^{\prime \prime}$.

En 1987 las Ediciones Universidad de Navarra publica sus Dos estudios sobre el Código de Ovando. En este volumen pasa revista a las "Ordenanzas de nuevos descubrimientos, poblaciones y pacificaciones" inclinándose por los años 1571-72 como fecha de redacción, llevada a cabo por Juan de Ovando con la colaboración de Juan López de Velasco. En opinión suya, no se trataría de un Código sino de una simple "recopilación y actualización de Instrucciones u Ordenanzas anteriores" ${ }^{15}$. En cuanto al segundo estudio reunido, éste está dedicado a analizar "El "Título de las Descripciones" del Código de Ovando", promulgado en 1573, consistente en una especie de cuestionario que debería orientar las descripciones geográficas.

Sin duda, la culminación de las pesquisas de fuentes legales indianas extraviadas fue hallar la Recopilación de Indias de Antonio León Pinelo, en 1986.

En la historia del Derecho Indiano se tenía una laguna en su conocimiento sobre lo emprendido en cuanto a recopilación de leyes desde 1603 a 1680. Se sabía que León Pinelo había elaborado un proyecto en tal sentido en 1636. De esta manera, la detectivesca pesquisa llevada a cabo por Sánchez Bella y el fructífero resultado le llevaba a estampar en 1987 :

"Esta pérdida del proyecto de Recopilación de León Pinelo, lamentada también por otros investigadores, ha terminado, pues desde ahora podemos contar felizmente con el texto íntegro elaborado por el infatigable funcionario del Consejo de Indias. El hallazgo es importante y vale la pena narrar cómo se ha conseguido" ${ }^{16}$.

El descubrimiento de 1986 rápidamente significó la estructuración de un equipo de trabajo; mientras el autor del hallazgo daba a conocer las peripecias de la localización de los cinco gruesos volúmenes en la principal revista alemana de historia americana, en 1987; un equipo de tres profesores del campo del Derecho de la

\footnotetext{
"SÁNCHEZ BELLA, Ismael, "Notas sobre Gaspar de Escalona y Juan Luis López, juristas del Virreinato peruano", en SÁNCHEZ BELLA, Derecho Indiano. Estudios II, op.cit.322-23. Y agrega sobre Juan Luis López, Marqués del Risco: "En todos sus trabajos, sobre el derecho Aragonés y sobre el Derecho Indiano, la "historia jurídica" la entiende como una historia de leyes y de glosas sobre esas leyes. Hasta final del siglo XIX esa concepción de Historia del Derecho como historia legal es la que seguirá predominando en autores como Sampere o Marichalar y Manrique. Es una concepción de la historia jurídica más erudita que científica y, en todo caso, incompleta" (Op.cit 324).

is SÁNCHEZ BELLA, Ismael, Dos estudios sobre el Código de Ovando, Ediciones Universidad de Navarra S.A., Pamplona, 1987,35.

${ }^{16}$ SÁNCHEZ BELLA, Ismael, "Hallazgo de la "Recopilación de las Indias" de León Pinelo", en SÁNCHEZ BELLA, Derecho Indiano. Estudios II, op.cit. 4.
} 
Universidad de Navarra empezaba el cotejo con la Recopilación de 1680, dando a conocer sus resultados en $1990^{17}$

Aun cuando, a juicio de Sánchez Bella y los colaboradores en el cotejo, se mantenía la incógnita sobre si las 243 leyes que tienen data entre 1635-1660 fueron o no recopiladas por el licenciado León Pinelo; a la labor de transcripción paleográfica llevada a cabo por cinco licenciados en Historia de la Universidad de Navarra, sucedió la edición de la misma: Esta se verificó en México, en 1992, con el concurso de la Escuela Libre de Derecho, los Gobierno de los Estados de Chiapas y de Morelos, el Instituto de Investigaciones Jurídicas de la Universidad Nacional Autónoma de México, las Universidades Cristóbal Colón, Navarra y Panamericana y el célebre librero - editor Miguel Angel Porrúa, con el título de Recopilación de las Indias por Antonio León Pinelo. Edición y estudio preliminar de Ismael Sánchez Bella.

En su estudio hizo notar Sánchez Bella, a propósito del título de la obra:

"En el manuscrito, el nombre utilizado es el de Recopilación de las Indias. Repasando los numerosos escritos de León Pinelo y los del rey y de los ministros del Consejo de Indias que pudieron conocer esa Recopilación, para ver la expresión utilizada para designarla, vemos que siempre se emplea la palabra Recopilación, pero varía la expresión completa. La más utilizada es la de "Recopilación de las Leyes de Indias", que alguna vez se alarga en la de "Recopilación de Leyes de las Indias Occidentales, Islas y Tierra Firme del Mar Océano" y, en otras ocasiones, se acorta en el de "Recopilación de las Indias", la misma que se usa en el manuscrito que examinamos" ${ }^{18}$.

Otras obras inéditas relativas al Derecho Indiano encontradas en los fondos documentales de la Biblioteca del Palacio Real o en la Biblioteca Nacional de Madrid, concernientes a los Visitadores, significaron modificar conclusiones provisorias sobre los nexos entre el Derecho Castellano y el Derecho Indiano.

\footnotetext{
${ }^{17}$ SÁNCHEZ BELLA, Ismael, "Cotejo de los Libros 7, 8 y 9 de la Recopilación de Indias de León Pinelo con los de 1680" en SÁNCHEZ BELLA, Nuevos estudios (Supra nota 2), op cit.100-117. Se concluía que la Recopilación de 1635 comprende 7.308 leyes, la de 1680 contiene 5.515. De las 7.308 leyes reunidas por León Pinelo, 5.723 pasaron a la Recopilación, o sea, un 78,3\%. "Puede, pues, afirmarse, que como nuestro cotejo ha demostrado, la Recopilación de León Pinelo de 1635 fue la fuente fundamental de la Recopilación definitiva de 1680 y que el mérito principal de la labor recopiladora corresponde al licenciado Antonio de León y no a Fernando Jiménez Paniagua. Hemos mostrado abundantísimas pruebas de la utilización directa de la Recopilación de 1635 en la preparación de la de 1680" (Op.cit. 115).

${ }^{18}$ SÁNCHEZ BELLA, Ismael, "Estudio preliminar", Recopilación de las Indias por Antonio León Pinelo, Miguel Angel PORRÚA LIBRERO- Editor - Instituto de Investigaciones Jurídicas, Universidad Nacional Autónoma de México, 1992, Tomo I, 26-27.
} 
Al dar noticia de las Ordenanzas del Visitador Tello de Sandoval, en México, de 1544, le permite a Sánchez Bella advertir a los investigadores americanistas sobre la vigencia del Derecho Castellano en el siglo XVI no tanto como supletorio sino, a veces, directamente:

"El autor de las Ordenanzas, canónigo e inquisidor, se muestra en todo momento excelente conocedor del Derecho vigente en Castilla... Creo conveniente resaltar aquí la importancia de la Colección de Pragmáticas, porque quizás muchos americanistas no han reparado en su importancia para la vida jurídica de las Indias durante el siglo XVI. En otros territorios, como en el reino de Navarra, las Leyes del Reino y las Pragmáticas reales se distinguen cuidadosamente, incluso coleccionándolas aparte, pero en Castilla y en las Indias esa separación se borra casi por completo... En las Indias, además de la norma de vigencia general de que se guarden, como derecho supletorio, "las leyes de nuestro Reino de Castilla, conforme a la Toro, así en quanto a la substancia, resolución y decisión de los casos, negocios y pleytos, como a la forma y orden de substancia", parece ser que leyes y pragmáticas de Castilla fueron de aplicación normal alli sin necesidad de sobrecarta especial hasta que ésta fue impuesta en $1626 \ldots$ La conclusión más importante a que se llega después de examinar las Ordenanzas de 1544 es confirmar la plena extensión a Indias del derecho castellano y su utilización como modelo para la elaboración de la legislación especial para Indias, y muy especialmente de la destinada a regular la administración de justicia... Lo mismo ocurre en buena parte de la administración de la Hacienda, donde se aplica también el "orden y estilo" de la Contaduría Mayor de Castilla.

No se crea, pues, que el Derecho castellano entra en vigor sólo con carácter supletorio y se piense en una innovación por el simple hecho de tratarse de una disposición para Indias. A medida que avance el estudio de las instituciones indianas se irá advirtiendo que la legislación indiana ha sido elaborada casi siempre sobre el molde de la castellana, ciñéndose a ella lo más posible. En el caso de las Ordenanzas de Tello de Sandoval, se intenta la trabazón orgánica de textos de Derecho castellano para facilitar su aplicación en Indias. La íntima unión de los nuevos territorios indianos a los que componen Castilla, que hace de aquéllos no una colonia, sino unas provincias más dentro de la monarquía española y la marcada impronta castellana en sus instituciones, queda una vez más puesta de relieve a través del examen del derecho promulgado expresamente para las Indias" ${ }^{19}$.

19 SÁNCHEZ BELLA, Ismael, "Ordenanzas del Visitador de la Nueva España, Tello de Sandoval, para la administración de justicia (1544)", en SÁNCHEZ BELLA, Derecho Indiano. Estudios I, op.cit. 252-255.

Al dar a publicidad las Ordenanzas del Visitador Palafox consigna que se está en presencia de un caso "quizás único en la historia del Derecho indiano: el de la intensa utilización de la famosa Recopilación de Indias elaborada por Antonio León Pinelo cerca de cuarenta años antes de ser promulgada en 1680". Cf. SÁNCHEZ BELLA, 
Al redactar el balance historiográfico de los estudios sobre las instituciones jurídicas indianas, en 1987, reparó que estos se habían vistos reforzados por la articulación - "la especial pujanza de tres grupos nacionales" acota- de grupos universitarios con la generación de revistas especializadas, como son el español, el argentino y el chileno; pero, también, de algunas novedades metodológicas, no tan sustantivas como para cuestionar severamente "el depurado método histórico-jurídico que ha venido utilizando la denominada Escuela de Hinojosa (que) ofrece todavía a los investigadores de las instituciones jurídicas indianas un camino sólido y seguro en su trabajo". Las pocas novedades metodológicas radicaban en la reconstrucción de "la osamenta legal (y) conocer cuál fue la realidad en la vida de cada institución. Quizás el tema que acusa más novedad metodológica es el de las Audiencias, cuyo estudio ha sido abordado no solamente desde el aspecto jurídico, sino también desde la "historia cuantitativa" y desde la "historia social de la Administración" ${ }^{20}$.

3. $\mathrm{Ha}$ sido la experiencia en los variados archivos, peninsulares e iberoamericanos, la propia enseñanza de la historia del derecho en variados cursos de pre-grado y doctorado, y la concurrencia a variados encuentros internacionales, las que han dado lugar, en nuestro autor, a una amplitud de los temas histórico - jurídicos tratados. Temas que, avalados en una riqueza de materiales documentales, han posibilitado reconstruir de la forma más "exacta" el pasado histórico. En todo ello, procurando la conjunción de la realidad legal y de la realidad social cotidiana; esta última, daría cuenta de los efectos de la aplicación de la norma en tierras novomundistas.

En este sentido, se congratulaba como los especialistas iberoamericanos estaban fijando su atención sobre "la costumbre" indígena o criolla y llamar la atención a que no bastaba sólo conocer la norma jurídica para saber del funcionamiento de las instituciones $y$, menos, para entender la aplicación de la ley en los territorios ultramarinos. O las "cosas debieron ser más sencillas de lo que nos imaginamos historiadores y juristas", reflexiona, a propósito de los oficios de Almirante, Virrey y Gobernador a los que aspiró Cristóbal Colón, para, seguidamente, apostillar: "todo esto indica una vez más la necesidad de renunciar a la idea de que las Recopilaciones (castellana e indiana) puedan servir como fuente histórica segura, si no se acude a los Registros donde se iban anotando los textos legislativos para Castilla (hoy, en el

Ismael, "Ordenanzas para los tribunales de México del Visitador Palafox (1646)", en SÁNCHEZ BELLA. Derecho Indiano, op.cit.357.

20

Ismael SÁNCHEZ BELLA, "Historiografía de las instituciones jurídicas indianas (1945-1987)" en SÁNCHEZ BELLA, Nuevos estudios, op.cit.305-306. En otro trabajo, "Aportación española a la historia del Derecho Indiano (1940-1989)", complementó las fichas bibliográficas (Cf. Sánchez Bella, Nuevos estudios, op.cit. 359-388), Consúltese asimismo el capitulo "Historiografía jurídica indiana" en SÁNCHEZ BELLA Ismael, Alberto de la Hera y Carlos DíAZ Rementeria, Historia del Derecho Indiano, Editorial Mapfre, Madrid, 1992,15-33. 
Archivo de Simancas) o para Indias (ahora, en el Archivo General de Indias de Sevilla). Tengo la impresión de que en el largo y fecundo reinado de los Reyes Católicos la organización administrativa sufrió notables innovaciones, todavía mal conocidas, y que, cuando se estudien, se aclarará definitivamente el tema del origen castellano de las instituciones indianas" ${ }^{21}$.

Sin duda que las fuentes no legales podían auxiliar para dar forma al panorama del funcionamiento de las instituciones indianas ${ }^{22}$.

Sánchez Bella publicó en 1975 en México un muy interesante artículo destinado a estrechar la colaboración entre historiadores y antropólogos, que suscribe plenamente, y, dado su especialización en el campo jurídico, dio nómina de fuentes susceptibles para ser empleadas por la etnología. De esta manera, la imagen del súbdito indígena americano podía ser elaborada a partir de las fuentes legales y no legales, peninsulares y criollas, para poder comprender, entonces, el impacto de la aplicación del derecho indiano durante más de tres siglos

III. Hemos revisado su concepción histórico - jurídica y como ésta se erige desde la propia y directa compulsa de los folios guardados en los distintos archivos que contrastar con otras fuentes que ayuden a bocetar no sólo la naturaleza jurídica de las instituciones sino la evidente influencia del entorno local americano en adecuar éstas a su realidad inmediata; de esta manera, poder matizar o derechamente transformar sus atribuciones en la administración española indiana.

Ahora, queremos, sucintamente, dar noticia de los estudios más señeros llevados a cabo por D.Ismael en el terreno del Derecho Indiano.

Su propio magisterio en la Universidad de Navarra ha establecido una verdadera Escuela Histórica - Jurídica, tanto en la vertiente Indiana como Española, cuyos

${ }^{21}$ SÁNCHEZ BELLA Ismael, "La organización política de la América española" en Sánchez Bella, Nuevos estudios, op.cit.151.

${ }^{22}$ Cf. el apartado sobre fuentes "No legislativas, de interés histórico-jurídico" de su trabajo "Aportación española a la historia del derecho Indiano (1940-1989)", p.364 (Supra nota 20), donde figuran Consultas del Consejo de Indias, Memorias de Virreyes, cartas de los Cabildos, Sinodos americanos, Cartas y relaciones de Indias.

Al estudiar, en 1980, "Quito, Audiencia subordinada" podía concluir, precisamente por el cotejo de las diversas fuentes, que "como ocurrió en tantos otros aspectos del Derecho indiano, la realidad histórica no se ajustó exactamente a las normas legales, ya que la Audiencia decidió en numerosos actos de gobierno, incluso en algunos que estaban reservados a los Virreyes". Cf. Ismael SÁNCHEZ BELLA, Derecho Indiano. Estudios II. op.cit. 547.

${ }^{23}$ SÁNCHEZ BELLA Ismael, "Las Indias. Instituciones de gobierno, estructura burocrática, jurisdicción y archivos (Siglos XVI y XVII" que fue originalmente una ponencia destinada al "Simposium de Etnología Histórica de España y las antiguas dependencias españolas" que debió celebrarse en Copenhague, pero fue publicada en México, y está recogida en SÁNCHEZ BELLA. Nuevos estudios, op.cit. pp. 131-142. 
resultados acadé micos se pueden reconocer fácilmente y sobre los cuales se ha hecho cargo en sus escritos ${ }^{24}$.

Habría cinco ámbitos donde se percibe ${ }^{25}-y$ justiprecia internacionalmente- la producción intelectual de Sánchez Bella, relativa al Derecho Indiano. Estos serían: uno, el insuperable estudio dedicado a La organización financiera de las Indias, siglo XVI, publicado en 1968 en Sevilla, que tendría una segunda edición facsimilar en Ciudad de México en 1990, 361 pp; dos, Iglesia y Estado en la América Española, con dos ediciones por Eunsa, Pamplona, 1990 y 1991,332 pp.; tres, las ediciones, con estudios preliminares suyos, de Antonio León Pinelo, Recopilación de las Indias, Ciudad de México, 1992, 3 volúmenes, y Rodrigo de Aguiar y Acuña y Juan Francisco Montemayor y Córdoba de Cuenca, "Sumarios de la Recopilación General de Leyes de las Indias Occidentales", Ciudad de México, 1994,Lii y 792 pp., y el volumen Dos estudios sobre el Código de Ovando, impreso en Pamplona en 1987,217 pp; cuatro, la colección de estudios reunidos en Derecho Indiano. Estudios I. Las visitas generales en la América española (Siglos XVI-XVII), Pamplona, 1991, 357 pp.; en Derecho Indiano. Estudios II. Fuentes. Literatura Jurídica. Derecho Público, Pamplona, 1991,695 pp.; y los Nuevos estudios de Derecho Indiano, Pamplona, 1995,404 pp.; y cinco, la Historia del Derecho Indiano, redactada con Alberto de la Hera y Carlos Díaz Rementería.

Es precisamente en esta última obra donde Sánchez Bella fija las nuevas consideraciones habidas sobre los distintos aspectos del Derecho Indiano, sea en sus fuentes legales como en sus diversas instituciones, destacándose los capítulos "Las fuentes del Derecho Indiano", que recoge el "estado de la cuestión" respecto a las fuentes, las colecciones de fuentes legales y la literatura jurídica indiana, y "La Administración" donde el lector común y el especialista hallará un friso completo, escrito llanamente, sobre la administración central, la territorial, local, la administración de justicia, la real hacienda, ejército y armada, el control de los funcionarios, para concluir con un "Juicio crítico sobre la administración española en

\footnotetext{
${ }^{24}$ CF. SÁNCHEZ BELLA Ismael, "Historiografía jurídica española" en Historia del Derecho Indiano (Supra nota 20), p.16.A modo de ejemplo, los doctores Joaquín Salcedo Izu, Mercedes GALÁN LORDA, Carmen PURROY TURRILLAS, del Departamento de Historia del Derecho de la Universidad de Navarra y las decenas de licenciados y doctores cuyos trabajos fueron dirigidos por D.Ismael SÁNCHEZ BELLA Cf. "Curriculum Vitae" de Ismael SÁNCHEZ BELLA, en Homenaje a SÁNCHEZ BELLA Ismael, op.cit. 24

25

Un panorama de los trabajos de D. Ismael sobre la historia moderna de España, además de las consignadas en nota 11, debería considerar: "La España que conoció el General San Martín (para la comprensión de la Independencia de América). Arbor (Madrid, 1951), número 63: "La vida cultural española en los últimos diez años", Cultura española contemporánea (Santa Fe, Argentina, 1952):Los Reinos en la Historia Moderna de España, Madrid, 1956; "Perfil humano de Angel López-Amo, historiador del derecho y pensador político", en Angel López - Amo y Marín, Pamplona, 1957; "La polémica sobre las fuentes de la Constitución española de 1812" . IV Congreso Internacional de Historia de América (Argentina, 1966);" El regalismo borbónico durante el Setecientos", y "Iglesia y Estado español en la Edad Moderna (Siglos XVI y XVII)" en EI Estado español en su dimensión histórica (Barcelona, 1984)
} 
América". En ese "Juicio crítico" suscribe las conclusiones de Zorraquín Becú y de García Gallo, donde el primero afirma que "no se llegó a un absolutismo total" y el segundo rechaza el "tópico de un "gobierno de contrapeso" en el que se buscaría, maquiavélicamente, enfrentar a las distintas autoridades, cuando en realidad se buscaba con empeño su actuación concorde" ${ }^{26}$.

Concluyamos esta aproximación a la visión histórico - jurídica de D. Ismael, evocando sus palabras en las IV Conversaciones Internacionales de Historia, cuando se pronunció ante los "ataques antiespañoles" a lo ejecutado durante tres siglos en América, que dada la cercanía de la fecha-hito de 1992, consideraba "un violento ataque a la verdad histórica" :

"Ante este ataque a la verdad histórica, me parece, no ya como español sino como historiador, que por un momento tenemos que pensar cuál es nuestro papel ante este ataque. Porque caben tres actitudes: el "mea culpa" que, por lo visto, algunos practican; otro, el tratar de desentenderse y el tercero, el de la polémica. Pienso que ni desentenderse, ni angustiarse, ni polemizar. Nuestro papel podría ser a dar, con serenidad, la verdad histórica, pero en una forma que sirva para difundir... la verdad respecto a estos tópicos... que son del momento actual y no coinciden con los de hace veinte años ni con los de hace cincuenta" ${ }^{27}$

${ }^{26}$ Cf. SÁNCHEZ BELLA Ismael, Alberto de la HERA y Carlos DiAZ Rementeria, Historia del Derecho Indiano. op.cit. 244 .

${ }^{27}$ "Debate IV", Balance de la Historiografía sobre Iberoamérica (1945-1988), op.cit. 513. 